\title{
The use of less invasive surfactant administration (LISA) in the United States with review of the literature
}

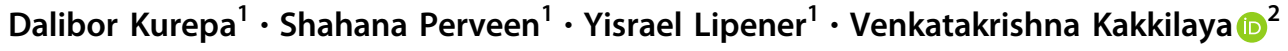

Received: 16 July 2018 / Revised: 17 November 2018 / Accepted: 6 December 2018 / Published online: 11 January 2019

(c) Springer Nature America, Inc. 2019

\begin{abstract}
Background The majority of extremely low gestational age neonates undergo intubation for surfactant therapy. Less invasive surfactant administration (LISA) uses a thin catheter inserted into the trachea to deliver the surfactant. During the procedure, the infant is breathing spontaneously while supported with continuous positive airway pressure. Although LISA is widely adapted in Europe and Australia, the rate of LISA use in the United States is unknown.

Study design The aim of this study is to evaluate the use of LISA in the US. A web-based survey was distributed via SurveyMonkey to 2550 neonatologists from AAP's SoNPM mailing list.

Results Of the 472 neonatologists who answered the survey, $15 \%$ used LISA either as a part of routine care (8\%) or as part of research $(7 \%)$.

Conclusion Unlike several regions of Europe, LISA is not widely used in the US. Future studies should address ambiguities regarding infant selection, procedure training and "roadblocks" to its broader application.
\end{abstract}

\section{Introduction}

The majority of extremely low gestational age neonates (ELGAN) admitted to neonatal intensive care unit (NICU) on continuous positive expiratory pressure (CPAP) require intubation for surfactant therapy. The harmful effect of mechanical ventilation (MV) on premature lungs with respiratory distress syndrome (RDS) has been well described. Even a brief exposure to large volume breaths could initiate an inflammatory cascade leading to bronchopulmonary dysplasia (BPD) [1-3]. Avoiding negative effects of longer term MV led to the development of the INSURE technique (INtubation-SURfactant administration-Extubation) [4]. This technique has been extensively accepted in NICUs around the world. Still, INSURE requires intubation with variable duration of $\mathrm{MV}$ after surfactant administration. In order to further decrease the

Dalibor Kurepa

dkurepa@northwell.edu

1 Cohen Children's Medical Center, New Hyde Park, NY, USA

2 University of Texas Southwestern Medical Center, Dallas, TX, USA exposure to intubation and MV, several methods of less invasive surfactant delivery have been evaluated.

There are four different techniques for less invasive surfactant delivery: surfactant administration via a thin catheter [4-22], aerosolized surfactant administration [23-27], pharyngeal surfactant administration [28-30] and laryngeal mask airway (LMA)-guided surfactant administration [31-36]. The most studied method has been surfactant instillation via thin catheter.

The terminology relating to the overall use of a thin catheter in surfactant delivery as well as the type of catheter have been inconsistent. The most commonly used term is LISA (less invasive surfactant administration), followed by MIST (minimally invasive surfactant therapy). The use of a feeding tube to instill surfactant in the airway has been the most prevalent technique (Cologne method, Take Care method, SONSURE method, etc.) $[8,12,15]$. Another wellstudied technique is the Hobart method, which uses a 16-G angiocatheter for surfactant delivery [7,9]. Table 1 depicts a comparison of all LISA techniques studied to date. We prefer the term LISA over MIST since the word "minimal" in MIST may appear ambiguous as the procedure still involves placing a catheter in neonate's airway.

Written in Danish, Verder et al. published the first study describing the use of a thin catheter to administer surfactant to premature infants with RDS who were managed with 
Table 1 Comparison of different LISA techniques

\begin{tabular}{|c|c|c|c|c|c|c|}
\hline Reference study & Method name & $\begin{array}{l}\text { Gestational } \\
\text { age (weeks) }\end{array}$ & $\begin{array}{l}\text { Type of thin } \\
\text { catheter }\end{array}$ & $\begin{array}{l}\text { Premedication } \\
\text { used }\end{array}$ & $\begin{array}{l}\text { Forceps } \\
\text { used }\end{array}$ & $\begin{array}{l}\text { Surfactant } \\
\text { type, dose } \\
\text { and } \\
\text { delivery } \\
\text { duration }\end{array}$ \\
\hline Kribs et al. [5] & Cologne & $23-27$ & $\begin{array}{l}\text { Feeding tube } \\
\text { (4F) }\end{array}$ & Yes (atropine) & Yes & $\begin{array}{l}\text { Survanta } \\
100 \mathrm{mg} / \mathrm{kg} \\
1-3 \mathrm{~min}\end{array}$ \\
\hline Dargaville et al. [9] & Hobart & $25-32$ & $\begin{array}{l}\text { Angiocatheter } \\
(16 \mathrm{G})\end{array}$ & Yes (sucrose) & No & $\begin{array}{l}\text { Curosurf } \\
100-200 \\
\mathrm{mg} / \mathrm{kg} \\
15-30 \mathrm{~s}\end{array}$ \\
\hline Aguar et al. [15] & SONSURE & $24-35$ & $\begin{array}{l}\text { Feeding tube } \\
(3.5-4 \mathrm{~F})\end{array}$ & Yes (atropine) & Yes & $\begin{array}{l}\text { Curosurf } \\
100 \mathrm{mg} / \mathrm{kg} \\
1-3 \mathrm{~min}\end{array}$ \\
\hline $\begin{array}{l}\text { Krajewski et al. } \\
\text { [19] }\end{array}$ & - & $\begin{array}{l}29 \text { (only } \\
\text { median } \\
\text { reported) }\end{array}$ & Feeding tube & No & Yes & $\begin{array}{l}\text { Curosurf } \\
100-200 \\
\mathrm{mg} / \mathrm{kg} \\
10-20 \mathrm{~s}\end{array}$ \\
\hline Kanmaz et al. [13] & Take care & $25-32$ & $\begin{array}{l}\text { Feeding tube } \\
(5 \mathrm{~F})\end{array}$ & No & No & $\begin{array}{l}\text { Curosurf } \\
100 \mathrm{mg} / \mathrm{kg} \\
30-60 \mathrm{~s}\end{array}$ \\
\hline $\begin{array}{l}\text { Mohammadizadeh } \\
\text { et al. [17] }\end{array}$ & - & $29-33$ & $\begin{array}{l}\text { Feeding tube } \\
(4 \mathrm{~F})\end{array}$ & Yes (atropine) & Yes & $\begin{array}{l}\text { Curosurf } \\
100 \mathrm{mg} / \mathrm{kg} \\
1-3 \mathrm{~min}\end{array}$ \\
\hline $\begin{array}{l}\text { Klebermans- } \\
\text { Schrehof et al. [11] }\end{array}$ & - & $23-27$ & $\begin{array}{l}\text { Feeding tube } \\
(4 \mathrm{~F})\end{array}$ & No & Yes & $\begin{array}{l}\text { Curosurf } \\
200 \mathrm{mg} / \mathrm{kg} \\
2-5 \mathrm{~min}\end{array}$ \\
\hline Bao et al. [18] & - & $28-32$ & $\begin{array}{l}\text { Angiocatheter } \\
(16 \mathrm{G})\end{array}$ & No & No & $\begin{array}{l}\text { Curosurf } \\
200 \mathrm{mg} / \mathrm{kg} \\
3-5 \mathrm{~min}\end{array}$ \\
\hline $\begin{array}{l}\text { Heidarzadeh et al. } \\
\text { [14] }\end{array}$ & - & $28-32$ & $\begin{array}{l}\text { Feeding tube } \\
(5 \mathrm{~F})\end{array}$ & No & No & $\begin{array}{l}\text { Curosurf } \\
200 \mathrm{mg} / \mathrm{kg} \\
-\end{array}$ \\
\hline Mehler et al. [10] & - & $22-26$ & $\begin{array}{l}\text { Feeding tube } \\
\text { (unknown } \\
\text { size) }\end{array}$ & No & No & $\begin{array}{l}\text { Survanta } \\
100 \mathrm{mg} / \mathrm{kg} \\
-\end{array}$ \\
\hline $\begin{array}{l}\text { Canals Candela } \\
\text { et al. [21] }\end{array}$ & - & $25-35$ & $\begin{array}{l}\text { Angiocatheter } \\
(16 \mathrm{G})\end{array}$ & No & No & $\begin{array}{l}\text { Curosurf } \\
200 \mathrm{mg} / \mathrm{kg} \\
1-2 \mathrm{~min}\end{array}$ \\
\hline
\end{tabular}

SONSURE Sonda Nasogástica Surfactante Extubación, $F$ French, $G$ gauge
CPAP only [12]. Several years later, Kribs et al. published a feasibility study showing decreased mortality in the LISA study group compared to historical controls [4]. Other pilot studies from NICUs around the world have shown LISA to be a feasible option in their respective settings [7, 10, 22].

Encouraging results from the initial small feasibility studies were followed by larger randomized controlled trials (RCT). The first RCT, Avoidance of Mechanical Ventilation (AVM), included 12 German NICUs. This study found that surfactant administration via a thin catheter reduces the need for intubation and MV [6]. Kanmaz et al. compared the LISA technique to INSURE in their Take Care Study and reported lower rates of both $\mathrm{MV}$ and BPD [13]. A large multicenter RCT conducted in Germany included over 200 ELGANs born at 23-26 weeks gestational age (GA)
(NINSAP trial). Although there was no difference in the primary outcome of composite death or BPD, important secondary outcomes such as pneumothorax, severe intraventricular hemorrhage (IVH) were lower while survival without major complications was higher in the LISA group. OPTIMIST-A is a large multicenter RCT that is currently underway. This study is powered to evaluate the composite outcome of BPD or death in a group of infants that had surfactant delivered with the Hobart method [37]. Several other smaller RCTs have also shown very encouraging results in favor of LISA [14, 17, 18].

To date four meta-analyses have been completed. Rigo et al. evaluated six RCTs. They found that LISA resulted in decreased risk of BPD, composite outcome death or BPD and the need for MV [38]. Another study pooled 30 RCTs 
(5598 neonates) to examine seven ventilation strategies: nasal CPAP alone, INSURE, LISA, nasal intermittent positive pressure ventilation (NIPPV), nebulized surfactant administration, surfactant administration via LMA, and MV. The use of LISA was associated with lower odds of the composite outcome of death or BPD and severe IVH. Calculation of the ranking possibilities found LISA to be the best strategy in this group of infants [39]. Similarly, a meta-analysis of three RCTs that compared LISA to INSURE found that LISA significantly reduced the need for $\mathrm{MV}$, duration of MV, duration of CPAP, duration of oxygen supplementation and a trend toward reduction of BPD [40]. Finally, the most recent systematic review involving six RCTs and 895 neonates with RDS confirmed that LISA significantly reduces BPD, composite outcome of BPD or death and the need for MV [41].

Several other studies looked at different aspects of LISA application. An animal study using preterm lambs found better oxygenation in lambs treated with LISA and CPAP vs. CPAP alone while $\mathrm{PaO}_{2}$ values were similar in the LISA and intubated lambs. This study, however, reported that lambs treated with LISA had slightly less surfactant distributed to the left upper lobe of the lung [42]. A recent study used near-infrared spectroscopy (NIRS) to examine cerebral autoregulation in neonates treated with LISA compared to INSURE. It described that autoregulation was affected for a shorter period of time in LISA patients [43]. Dargaville et al. analyzed the impact of surfactant administration via catheter on CPAP failure. They showed that CPAP failure was avoided in $14 \%$ of infants treated with LISA compared to $7 \%$ that were treated with CPAP alone [44]. A novel study used LMA (connected to T-piece resuscitator) to guide the catheter during surfactant delivery in mannequins (CALMEST-Catheter And LMA Endotracheal Surfactant Therapy). Researchers concluded that this approach was quick, effective and well tolerated where it may be an alternative approach for medical staff that lack expertise in laryngoscopy and intubation [45]. Another prospective observational study noted changes in tidal volumes (TV) and end-expiratory lung volumes (EELV) before and after LISA by using electrical impedance tomography. They recorded rapid and sustained increase in EELV that correlated positively with an increase in oxygenation [46].

Studies regarding sedation and procedural side effects of LISA have also been published. A retrospective study from the Netherlands demonstrated that COMFORTneo scores were lower indicating a higher comfort level in neonates sedated during LISA although the duration of bradycardia and hypotension was similar in both groups. Conversely, the use of sedation resulted in more frequent desaturations and the need for positive pressure ventilation (PPV) [47]. Common short-term side effects such as cough, apnea, bradycardia and desaturations were relieved with slower surfactant delivery [6]. Challenging catheter placement, need for PPV via facial mask, unilateral surfactant deposition and gastric instillation may occur as well [16]. A fairly recent manuscript described a LISA simulation that examined catheter preferences from 20 neonatologists. Subjectively, the majority of physicians preferred a slightly more rigid catheter, such as an umbilical venous catheter with a stylet [48].

Finally, two studies reported long-term outcomes data. Follow-up information on LISA infants from Germany at 3 years corrected age compared long-term data during two periods, 18 months before and 18 months after LISA introduction. Both Mental and Physical Developmental Indices improved following LISA introduction (89 vs. 98, $p=0.16,83$ vs. 91, $p=0.03$, respectively) [49]. Another study from Europe observed historical controls and surfactant without intubation group (SWI). They found no statistically significant differences regarding neurodevelopmental outcomes at school age [50].

\section{Methods}

In March and April 2018, we conducted a web-based survey designed to assess the current use of LISA in NICUs across the United States. The survey was structured as a questionnaire and distributed using SurveyMonkey (San Mateo, CA). This study was approved by the Institutional Review Board (Northwell Health, Great Neck, NY). Our survey consisted of 15 questions. The first six questions (Table 2) focused on general information regarding participants' demographic data, knowledge and interest in LISA. Subsequently, participants were asked to select whether they used LISA in their units. Only those participants who used LISA were routed to additional usage-specific questions about LISA (Table 3). Our survey was disseminated to the members of the American Academy of Pediatrics (AAP) Section on Neonatal-Perinatal Medicine (SoNPM) via an email link. Respondents were anonymous and limited to one response per individual.

\section{Results}

Of the 2550 neonatologists who were included in the AAP SoNPM mailing list, 472 (18\%) responded to the survey.

\section{General answers}

Sixty-six percent of the responding neonatologists worked in an academic setting (Table 2). The vast majority $(97 \%)$ worked at level 3-4 NICUs with $66 \%$ of the respondents administering surfactant at least 50 times per year. In regards to the question concerning introduction of LISA in 
Table 2 General questions and answers

\begin{tabular}{|c|c|}
\hline General questions and answers & $\begin{array}{l}\text { Number }(\%) \text { of } \\
\text { respondents } \\
n=472\end{array}$ \\
\hline \multicolumn{2}{|l|}{ In what setting do you practice neonatology? } \\
\hline Academic NICU & $311(65.89)$ \\
\hline Non-academic NICU & $161(34.11)$ \\
\hline \multicolumn{2}{|c|}{ Please indicate the highest level of NICU care available in your center. } \\
\hline Level II & $16(3.39)$ \\
\hline Level III & $194(41.10)$ \\
\hline Level IV & $262(55.51)$ \\
\hline \multicolumn{2}{|c|}{ How many times per year is surfactant administered in your NICU? } \\
\hline Very rarely & $6(1.28)$ \\
\hline$<20$ & $40(8.50)$ \\
\hline $20-50$ & $114(24.26)$ \\
\hline $50-100$ & $126(26.81)$ \\
\hline$>100$ & $184(39.15)$ \\
\hline \multicolumn{2}{|c|}{ Has your NICU ever discussed introduction of LISA? } \\
\hline $\begin{array}{l}\text { Yes, formally through a 'review of the } \\
\text { literature' session or lecture }\end{array}$ & $128(27.23)$ \\
\hline Not at all & $112(23.83)$ \\
\hline Only in informal conversations & $230(48.94)$ \\
\hline \multicolumn{2}{|c|}{$\begin{array}{l}\text { Do you believe that the current literature on LISA is strong enough to } \\
\text { recommend it as a standard of care? }\end{array}$} \\
\hline Yes & $47(9.96)$ \\
\hline No & $63(13.35)$ \\
\hline More evidence is needed & $200(42.37)$ \\
\hline Not sure & $162(34.32)$ \\
\hline \multicolumn{2}{|l|}{ Do you use LISA in your NICU? } \\
\hline Yes & $19(4.04)$ \\
\hline No & $397(84.47)$ \\
\hline Sometimes & $20(4.26)$ \\
\hline Only as a part of research study & $34(7.23)$ \\
\hline
\end{tabular}

the NICU, $27 \%$ of physicians had a formal literature review on the topic, $49 \%$ had an informal conversation about it and $24 \%$ had no discussion at all. Ten percent of the respondents believed that the current literature on LISA is strong enough to recommend it as standard of care, $13 \%$ of respondents felt that the literature is not strong enough, $42 \%$ believed more evidence is needed and the remaining 34\% were not sure. Currently, $15 \%$ of physicians are using LISA in their NICU either all the time (4\%), sometimes $(4 \%)$, or only as part of a research study (7\%).

\section{LISA-usage specific answers}

Among those who were using LISA, 56\% had a guideline or protocol for its use (Table 3). With respect to the lowest GA at which LISA was used, $24 \%$ of physicians considered it safe in neonates <26 weeks GA, 14\% thought it was safe in 26-28 weeks GA neonates and $18 \%$ believed it was only safe for a GA $>28$ weeks. Most neonatologists (45\%), however, were unsure about the lowest GA LISA could be used safely. About 2/3 (72\%) of physicians who use LISA did not have any prior formal training on a mannequin while $94 \%$ did not routinely use any form of sedation. Furthermore, $46 \%$ of physicians used feeding tubes for surfactant administration, 20\% used angiocatheters (Hobart method), $4 \%$ used umbilical catheters and $30 \%$ used other methods that were not specified. Most physicians (86\%) did not use Magill forceps when placing a catheter into the trachea during LISA. In a situation where a repeat surfactant dose was needed, $77 \%$ of respondents tended to use LISA again. Approximately 1/3 (38\%) of physicians allowed 1-2 min for surfactant delivery, about 1/3 (29\%) allowed more than $3 \mathrm{~min}$ and the remainder either allow $<1 \mathrm{~min}$ or between 2 and $3 \mathrm{~min}$ (19\% and 13\%, respectively). Based on their experiences with LISA, $63 \%$ of the respondents believe it is a safe procedure.

\section{Discussion}

In the past 10 years, intensive studying on LISA technique has shown very promising results in the optimization of noninvasive ventilator support of infants with RDS. Most of the initial studies as well as subsequent long-term outcome data originated in Europe and Australia. Therefore, it is not surprising that many European countries have accepted LISA as standard of care in a selected group of premature infants on CPAP. However, there is still a wide variation regarding many aspects of the LISA method. Major questions include the use of feeding tube vs. angiocatheter for surfactant instillation, the exact patient population that may benefit from this approach (GA, oxygen requirement or RDS severity) and procedure training process. Furthermore, standardization of sedation use is lacking as about half of the physicians (52\%) premedicate their neonates [51]. Surfactant dosing has also been inconsistent with a suggestion that higher doses may be needed for a prolonged effect. Likewise, duration of surfactant delivery varies from $30 \mathrm{~s}$ to $5 \mathrm{~min}[6,7,13,16]$. The latter two facts may be directly proportional to the incidence of side effects encountered with LISA. Even though there are several studies about each of the LISA techniques, there is no study directly comparing the various methods. At the same time, these studies should involve experienced clinicians to assure low failure rate when examining each method. Thus, making recommendations on which technique to use may be challenging.

Although previous studies among neonatologists in Europe and Australia showed increased interest in LISA, no studies reported the current practice trend in the US $[51,52]$. We aimed to investigate the neonatologists' knowledge, attitude and practices regarding the LISA 
approach. Our survey was cautiously structured to examine the general knowledge on this topic as well as LISA-usagespecific questions only offered to those physicians that have been using LISA already.

Two-thirds of the respondents came from academic NICUs with the vast majority practicing in level 3 and 4 NICUs centers that commonly use surfactant in their practice. Only $24 \%$ of the respondents never discussed the use of LISA in their institutions, where the remainder reviewed it either formally or informally. These percentages clearly show that there is a distinct interest in LISA in the United States. On the other hand, only $10 \%$ of the neonatologists believe that the literature on LISA is strong enough to be recommended as standard of care. Most are either not sure or need more data before they would consider it as standard practice. Consequently, LISA usage in the United States has been found to be $15 \%$, whether it be consistent or in constant practice or as part of research. We also believe that another reason for the low rate of LISA use in the US is the lack of structured training in the LISA method. This method may or may not involve the use of Magill forceps that requires sizeable manual dexterity.

LISA-usage-specific questions revealed that few neonatologists practice the technique on a mannequin before applying the procedure to their patients. It is unclear if this relatively low number may be due to the fact that most of the users may be more experienced neonatologists who are more than comfortable with the intubation process. Approximately half of the neonatologists have written guidelines or policies for LISA use. Unexpectedly, very few babies received sedation prior to the procedure despite its popularity across European countries. Refrainment from sedative use may be due to the above-mentioned complications. Most physicians seem to use a feeding tube or an angiocatheter, $46 \%$ and $20 \%$ respectively. Only a minority of neonatologists use Magill forceps to facilitate endotracheal placement of the catheter. This fact may indicate either comfort with the procedure itself or reluctance to the use of the forceps. Major discrepancies were seen for the time allotted for surfactant delivery. Overall, the majority of neonatologists will distribute the surfactant fairly slowly, over 1 min or more. We speculate that rapid administration of surfactant was reserved for more mature neonates who are less prone to the side effects. Lastly, only a marginal number of respondents believed that LISA is an unsafe procedure, with majority accepting it as being benign. Surprisingly, almost $1 / 4$ of neonatologists feel it is safe to use the LISA even in neonates $<26$ weeks GA.

Our survey response rate (18\%) was above average (10$15 \%$ ) for usual surveys conducted through the AAP SoNPM mailing list [53]. While our survey adds more data to the overall trends in LISA technique use, it is limited by the fact that we report individual neonatologists'
Table 3 LISA usage-specific questions and answers

\begin{tabular}{ll}
\hline $\begin{array}{l}\text { LISA usage-specific questions and } \\
\text { answers }\end{array}$ & $\begin{array}{l}\text { Number (\%) of respondents } \\
n=73\end{array}$
\end{tabular}
If you use LISA do you have a guideline or protocol for its use?

$\begin{array}{ll}\text { Yes } & 36(56.25) \\ \text { No } & 28(43.75)\end{array}$

In your opinion, what is the lowest gestational age at which LISA can be used safely and effectively?

$\begin{array}{lr}<26 \text { weeks GA } & 16(24.24) \\ 26-28 \text { weeks GA } & 9(13.64) \\ >28 \text { weeks GA } & 12(18.18) \\ \text { Not sure } & 29(43.94)\end{array}$

Do you provide a formal LISA training on a mannequin at your institution?

$$
\begin{array}{ll}
\text { Yes } & 18(27.69) \\
\text { No } & 47(72.31)
\end{array}
$$

Do you use any sedation when using

LISA?

$$
\begin{array}{lc}
\text { Yes } & 4(6.35) \\
\text { No } & 59(93.65)
\end{array}
$$

What LISA method is used in your NICU?

$\begin{array}{lc}\text { Feeding tube } & 25(46.30) \\ \text { Angiocatheter (Hobart method) } & 11(20.37) \\ \text { Umbilical catheter } & 2(3.70) \\ \text { Other } & 16(29.63)\end{array}$

Do you use Magill forceps when placing a catheter in trachea during LISA procedure?
Yes
$8(14.29)$
No
$48(85.71)$

Would you consider LISA again in an infant that needs a repeat dose of surfactant after $12 \mathrm{~h}$ ?
Yes
43 (76.79)
No
$13(23.21)$

Approximately how much time do you allow for surfactant delivery when using LISA?

$$
\begin{array}{lr}
<1 \mathrm{~min} & 10(19.23) \\
1-2 \mathrm{~min} & 20(38.46) \\
2-3 \mathrm{~min} & 7(13.46) \\
>3 \mathrm{~min} & 15(28.85)
\end{array}
$$

Based on your experience with LISA, do you believe it is a safe procedure?
Yes
$36(63.16)$
No
Not sure
$19(33.33)$

preferences and practices rather than NICU-specific data. Even though the number of respondents is robust, it may not completely describe the general data on LISA approach in the United States since we contacted only the members of AAP SoNPM. In addition, we could not confirm that all the members received and had the opportunity to answer the survey. 


\section{Conclusion}

Current evidence suggests that the LISA method in general may advance non-invasive respiratory support in premature neonates with RDS. The use of this method in the US is not as vigorous as in Europe but it has been present clinically and in research. Future studies are expected to further clarify lingering questions regarding patient selection, the type of thin catheter use, the procedural efficacy and safety of LISA. Therefore, more data from the US and other countries is strongly encouraged. Data from studies exploring other methods of less invasive surfactant delivery should also be closely monitored.

Acknowledgements Special thanks to Dr. James Cummings for his comments and help with editing this article. We also thank Jithin John, DO student, for the help with data processing.

Funding No funding has been received for this study.

\section{Compliance with ethical standards}

Conflict of interest The authors declare that they have no conflict of interest.

Publisher's note: Springer Nature remains neutral with regard to jurisdictional claims in published maps and institutional affiliations.

\section{References}

1. Hillman NH, Kallapur SG, Pillow JJ, Moss T, Polglase G, et al. Airway injury from initiating ventilation in preterm sheep. Pediatr Res. 2010;67:60-5.

2. Hillman NH, Moss TJ, Kallapur SG, Bachurski C, Pillow JJ, et al. Brief, large tidal volume ventilation initiates lung injury and a systemic response in fetal sheep. Am J Respir Crit Care Med. 2007; 176:575-81.

3. Stevens TP, Harrington EW, Blennow M, Soll RF. Early surfactant administration with brief ventilation vs. selective surfactant and continued mechanical ventilation for preterm infants with or at risk for respiratory distress syndrome. Cochrane Database Syst Rev. 2007;CD003063.

4. Kribs A, Pillekamp F, Hünseler C, Vierzig A, Roth B. Early administration of surfactant in spontaneous breathing with nCPAP: feasibility and outcome in extremely premature infants (postmenstrual age $</=27$ weeks). Paediatr Anaesth. 2007;17:364-9.

5. Kribs A, Härtel C, Kattner E, Vochem M, Kuster H, Moller J, et al. Surfactant without intubation in preterm infants with respiratory distress: first multi-center data. Klin Padiatr. 2010;222:13-7.

6. Göpel W, Kribs A, Ziegler A, Laux R, Hoehn T, Wieg C, et al. Avoidance of mechanical ventilation by surfactant treatment of spontaneously breathing preterm infants (AMV): an open-label, randomised, controlled trial. Lancet. 2011;378:1627-34.

7. Dargaville PA, Aiyappan A, Cornelius A, Williams C, De Paoli AG. Preliminary evaluation of a new technique of minimally invasive surfactant therapy. Arch Dis Child Fetal Neonatal Ed. 2011;96:F243-8.
8. Kribs A, Vierzig A, Hünseler C, Eifinger F, Welzing L, Stützer, et al. Early surfactant in spontaneously breathing with nCPAP in ELBW infants: a single centre four year experience. Acta Paediatr. 2008;97:293-8.

9. Dargaville PA, Aiyappan A, De Paoli AG, Kuschel CA, Kamlin $\mathrm{CO}$, Carlin JB, et al. Minimally-invasive surfactant therapy in preterm infants on continuous positive airway pressure. Arch Dis Child Fetal Neonatal Ed. 2013;98:F122-6.

10. Mehler K, Grimme J, Abele J, Huenseler C, Roth B, Kribs A, et al. Outcome of extremely low gestational age newborns after introduction of a revised protocol to assist preterm infants in their transition to extrauterine life. Acta Paediatr. 2012;101:1232-9.

11. Klebermass-Schrehof K, Wald M, Schwindt J, Grill A, Prusa AR, Haiden $\mathrm{N}$, et al. Less invasive surfactant administration in extremely preterm infants: impact on mortality and morbidity. Neonatology. 2013;103:252-4.

12. Verder H, Agertoft L, Albertsen P, Christensen NC, Curstedt T, Ebbesen F, et al. Surfactant treatment of newborn infants with respiratory distress syndrome primarily treated with nasal continuous positive air pressure. A pilot study. Ugeskr Laeger. 1992;154:2136-9.

13. Kanmaz HG, Erdeve O, Canpolat FE, Mutlu B, Dilmen U. Surfactant administration via thin catheter during spontaneous breathing: randomized controlled trial. Pediatrics. 2013;131:e502-9.

14. Heidarzadeh M, Mirnia K, Hoseini MB, Sadeghnia A, Akrami F, Balila M, et al. Surfactant administration via thin catheter during spontaneous breathing: randomized controlled trial in Alzahra hospital. Iran J Neonatol. 2013;4:5-9.

15. Aguar M, Cernada M, Brugada M, Gimeno A, Gutierrez A, Vento $\mathrm{M}$, et al. Minimally invasive surfactant therapy with a gastric tube is as effective as the intubation, surfactant, and extubation technique in preterm babies. Acta Paediatr. 2014;103:e229-33.

16. Kribs A, Roll C, Göpel W, Wieg C, Groneck P, Laux R, et al. Nonintubated surfactant application vs conventional therapy in extremely preterm infants: a randomized clinical trial. JAMA Pediatr. 2015;169:723-30.

17. Mohammadizadeh M, Ardestani AG, Sadeghnia AR. Early administration of surfactant via a thin intratracheal catheter in preterm infants with respiratory distress syndrome: feasibility and outcome. J Res Pharm Pract. 2015;4:31-6.

18. Bao Y, Zhang G, Wu M, Ma L, Zhu J. A pilot study of less invasive surfactant administration in very preterm infants in a Chinese tertiary center. BMC Pediatr. 2015;15:21.

19. Krajewski P, Chudzik A, Strzałko-Głoskowska B, Górska M, Kmiecik M, Więckowska K, et al. Surfactant administration without intubation in preterm infants with respiratory distress syndrome--our experiences. J Matern Fetal Neonatal Med. 2015;28:1161-4.

20. Göpel W, Kribs A, Härtel C, Müller T, Jorch G, Felderhoff-Müser $\mathrm{U}$, et al. Less invasive surfactant administration is associated with improved pulmonary outcomes in spontaneously breathing preterm infants. Acta Paediatr. 2015;104:241-6.

21. Canals Candela FJ, Vizcaíno Díaz C, Ferrández Berenguer MJ, Serrano Robles MI, Vázquez Gomis C, Quiles Durá JL, et al. Surfactant replacement therapy with a minimally invasive technique: Experience in a tertiary hospital. An Pediatr (Barc). 2016;84:79-84.

22. Ramos-Navarro C, Sánchez-Luna M, Zeballos-Serato S, González-Pacheco N. Less invasive beractant administration in preterm infants: a pilot study. Clinics (Sao Paulo). 2016;71:12834. https://doi.org/10.6061/clinics/2016(03)02.

23. Arroe M, Pedersen-Bjergaard L, Albertsen P, Bode S, Greisen G, Jonsbo F, et al. Inhalation of aerosolized surfactant (Exosurf1) to neonates treated with nasal continuous positive airway pressure. Prenat Neonat Med. 1998:3:346-52. 
24. Berggren E, Liljedahl M, Winbladh B, Andreasson B, Curstedt T, Robertson B, et al. Pilot study of nebulized surfactant therapy for neonatal respiratory distress syndrome. Acta Paediatr. 2000;89:460-4.

25. Jorch G, Hartl H, Roth B, Kribs A, Gortner L, Schaible T, et al. Surfactant aerosol treatment of respiratory distress syndrome in spontaneously breathing premature infants. Pediatr Pulmonol. 1997;24:222-4.

26. Finer NN, Merritt TA, Bernstein G, Job L, Mazela J, Segal R. An open label, pilot study of Aerosurf ${ }^{\circledR}$ combined with nCPAP to prevent RDS in preterm neonates. J Aerosol Med Pulm Drug Deliv. 2010;23:303-9.

27. Minocchieri S, Berry CA, Pilow JJ, CureNeb Study Team. Nebulised surfactant to reduce severity of respiratory distress: a blinded, parallel, randomised controlled trial. Arch Dis Child Fetal Neonatal Ed. 2018 Jul 26. pii: fetalneonatal-2018-315051. https:// doi.org/10.1136/archdischild-2018-315051.

28. Ten centre trial of artificial surfactant (artificial lung expanding compound) in very premature babies. Ten Centre Study Group. Br Med J (Clin Res Ed). 1987;294:991-6.

29. Dambeanu JM, Parmigiani S, Marinescu B, Bevilacqua G. Use of surfactant for prevention of respiratory distress syndrome in newborn infants in spontaneous breathing. A randomized multicentre clinical pilot-study. Acta Biomed Ateneo Parm. 1997;68 (Suppl 1):39-45.

30. Kattwinkel J, Robinson M, Bloom BT, Delmore P, Ferguson JE. Technique for intrapartum administration of surfactant without requirement for an endotracheal tube. J Perinatol. 2004;24:360-5.

31. Barbosa RF, Marcatto Jde O, Silva AC, Silva YP. ProSeal ${ }^{\mathrm{TM}}$ laryngeal mask airway for surfactant administration in the treatment of respiratory distress syndrome in a premature infant. Rev Bras Ter Intensiva. 2012;24:207-10.

32. Sadeghnia A, Tanhaei M, Mohammadizadeh M, Nemati M. A comparison of surfactant administration through i-gel and ET-tube in the treatment of respiratory distress syndrome in newborns weighing more than 2000 grams. Adv Biomed Res. 2014;3:160.

33. Pinheiro JM, Santana-Rivas Q, Pezzano C. Randomized trial of laryngeal mask airway versus endotracheal intubation for surfactant delivery. J Perinatol. 2016;36:196-201.

34. Attridge JT, Stewart C, Stukenborg GJ, Kattwinkel J. Administration of rescue surfactant by laryngeal mask airway: lessons from a pilot trial. Am J Perinatol. 2013;30:201-6.

35. Brimacombe J, Gandini D, Keller C, Parotto M, Doglioni N, Trevisanuto D. The laryngeal mask airway for administration of surfactant in two neonates with respiratory distress syndrome. Paediatr Anaesth. 2004;14:188-90.

36. Micaglio M, Zanardo V, Ori C, Parotto M, Doglioni N, Trevisanuto D, et al. ProSeal LMA for surfactant administration. Paediatr Anaesth. 2008;18:91-2.

37. Dargaville PA, Kamlin CO, De Paoli AG, Carlin JB, Orsini F, Soll RF, et al. The OPTIMISTA trial: evaluation of minimallyinvasive surfactant therapy in preterm infants 2528 weeks gestation. BMC Pediatr. 2014;14:213.

38. Rigo V, Lefebvre C, Broux I. Surfactant instillation in spontaneously breathing preterm infants: a systematic review and metaanalysis. Eur J Pediatr. 2016;175:1933-42.

39. Isayama $\mathrm{T}$, Iwami $\mathrm{H}$, Mcdonald $\mathrm{S}$, Beyene J. Association of noninvasive ventilation strategies with mortality and bronchopulmonary dysplasia among preterm infants: a systematic review and meta-analysis. JAMA. 2016;316:611-24. https://doi.org/10. 1001/jama.2016.10708.
40. Lau C, Chamberlain R, Sun S. Less invasive surfactant administration reduces the need for mechanical ventilation in preterm infants: a metaanalysis. Glob Pediatr Health. 2017;4:2333794X17696683. https:// doi.org/10.1177/2333794X17696683.

41. Aldana-Aguirre JC, Pinto m, Featherstone R, Kumar M. Less invasive surfactant administration versus intubation for surfactant delivery in preterm infants with respiratory distress syndrome: a systematic review and meta-analysis. Arch Dis Child Fetal Neonatal Ed. 2017;102:F17-23.

42. Niemarkt HJ, Kuypers E, Jellema R. Effects of less-invasive surfactant administration on oxygenation, pulmonary surfactant distribution, and lung compliance in spontaneously breathing preterm lambs. Pediatr Res. 2014;76:166-70. https://doi.org/10. 1038/pr.2014.66.

43. Li X, Cheng T, GuanR, Liang H, Lu WN, Zhang JH, et al. Effects of different surfactant administrations on cerebral autoregulation in preterm infants with respiratory distress syndrome. J Huazhong Univ Sci Technol Med Sci. 2016;36:801-5.

44. Dargaville PA, Ali SKM, Jackson HD, Williams C, De Paoli AG. Impact of minimally invasive surfactant therapy in preterm infants at 29-32 weeks gestation. Neonatology. 2018;113:7-14. https:// doi.org/10.1159/000480066.

45. Vannozzi I, Ciantelli M, Moscuzza F, Scaramuzzo RT, Panizza D, et al. Catheter and laryngeal mask endotracheal surfactant therapy: the CALMEST approach as a novel MIST technique. J Matern Fetal Neonatal Med. 2017;30:2375-7. https://doi.org/10.1080/ 14767058.2016.1248938.

46. van der Burg PS, de Jongh FH, Miedema M, Frerichs I, van Kaam $\mathrm{AH}$. Effect of minimally invasive surfactant therapy on lung volume and ventilation in preterm infants. J Pediatr. 2016;170:6772. https://doi.org/10.1016/j.jpeds.2015.11.035.

47. Dekker J, Lopriore E, Rijken M, Rijntjes-Jacobs E, Smits-Wintjens, Te Pas A. Sedation during minimal invasive surfactant therapy in preterm infants. Neonatology. 2016;109:308-13. https://doi.org/10.1159/000443823.

48. Rigo V, Debauche C, Maton P, Broux I, Van Laere D, et al. Rigid catheters reduced duration of less invasive surfactant therapy procedures in manikins. Acta Paediatr. 2017;106:1091-6. https:// doi.org/10.1111/apa.13850.

49. Tieg N, Weitkämper A, Rothermel J, Bigge N, Lilienthal E, Rossler L, et al. Observational study on Less Invasive Surfactant Administration (LISA) in preterm infants $<29$ weeks--short and long-term outcomes. Z Geburtshilfe Neonatol. 2015;219:266-73. https://doi.org/10.1055/s-0035-1547295.

50. Porath M, Korp L, Wendrich D, Dlugay V, Roth B, Kribs A. Surfactant in spontaneous breathing with nCPAP: neurodevelopmental outcome at early school age of infants $\leq 27$ weeks. Acta Paediatr. 2011;100:352-9. https://doi.org/10.1111/j.1651-2227. 2010.02068.x.

51. Klotz D, Porcaro U, Fleck T, Fuchs H. European perspective on less invasive surfactant administration-a survey. Eur J Pediatr. 2017;176:147-54. https://doi.org/10.1007/s00431-0162812-9.

52. Heiring C, Jonsson B, Andersson S, Bjorklund LJ. Survey shows large differences between the Nordic countries in the use of less invasive surfactant administration. Acta Paediatr. 2017;106:3826. https://doi.org/10.1111/apa.13694.

53. Feltman D, Du H, Leuthner S. Survey of neonatologists' attitudes toward limiting life-sustaining treatments in the neonatal intensive care unit. J Perinatol. 2012;32:886-92. 